\title{
An Agent-Based Model of Evolving Community Flood Risk
}

\author{
Gina L. Tonn ${ }^{1, *}$ and Seth D. Guikema ${ }^{2}$
}

\begin{abstract}
Although individual behavior plays a major role in community flood risk, traditional flood risk models generally do not capture information on how community policies and individual decisions impact the evolution of flood risk over time. The purpose of this study is to improve the understanding of the temporal aspects of flood risk through a combined analysis of the behavioral, engineering, and physical hazard aspects of flood risk. Additionally, the study aims to develop a new modeling approach for integrating behavior, policy, flood hazards, and engineering interventions. An agent-based model (ABM) is used to analyze the influence of flood protection measures, individual behavior, and the occurrence of floods and nearmiss flood events on community flood risk. The ABM focuses on the following decisions and behaviors: dissemination of flood management information, installation of community flood protection, elevation of household mechanical equipment, and elevation of homes. The approach is place based, with a case study area in Fargo, North Dakota, but is focused on generalizable insights. Generally, community mitigation results in reduced future damage, and individual action, including mitigation and movement into and out of high-risk areas, can have a significant influence on community flood risk. The results of this study provide useful insights into the interplay between individual and community actions and how it affects the evolution of flood risk. This study lends insight into priorities for future work, including the development of more in-depth behavioral and decision rules at the individual and community level.
\end{abstract}

KEY WORDS: Agent-based model; flood risk; flood mitigation

\section{INTRODUCTION}

Flooding is the most common natural hazard and the third most damaging globally, behind storms and earthquakes. ${ }^{(1)}$ Flood damage and flood risk continue to increase in the United States and abroad. ${ }^{(1,2)}$ This research investigates how behavior, policy, and engineering interventions impact riverine flood risk.

\footnotetext{
${ }^{1}$ Wharton Risk Management and Decision Processes Center, University of Pennsylvania, Philadelphia, PA, USA.

${ }^{2}$ Department of Industrial \& Operations Engineering, University of Michigan, Ann Arbor, MI, USA.

*Address correspondence to Gina L. Tonn, Wharton Risk Management and Decision Processes Center, University of Pennsylvania, 3819 Chestnut Street, Suite 130, Philadelphia, PA 19104, USA; gtonn@wharton.upenn.edu.
}

The purpose of this research is to inform flood mitigation and adaptation decision making.

Flood risk is often studied using hydrologic and hydraulic models, and flood risk management decisions are made based on these models together with benefit-cost calculations and considerations of acceptable risk levels. However, these models encompass considerable uncertainty about flood risk, and do not capture impacts of community policies and individual decisions on the evolution of flood risk over time. Individual behavior, including the decision to implement mitigation, to move into or out of flood-prone areas, and to purchase insurance, plays a major role in community flood risk.

Community flood risk is managed through regulations, insurance, and mitigation projects. Flood 
mitigation projects can be implemented on a community or a regional basis and may include soft measures like warning systems and evacuation plans, and hard measures like levees and dams. These measures are undertaken to reduce property damage and increase public safety. However, poorly planned or executed flood mitigation projects can have unanticipated consequences, such as reduced ecosystem services, and can even result in increased flooding and reduced public safety. ${ }^{(3)}$ Furthermore, flood control measures can create more damage by enticing development in marginally protected areas. This creates a cycle of development and structural flood mitigation. ${ }^{(4)}$ Consideration of the behavioral aspects of flood risk is crucial to minimizing these negative flood mitigation consequences, particularly when examining the evolution of flood risk over time in a given location.

The purpose of this study is to improve the understanding of the temporal aspects of community flood risk through a combined analysis of the behavioral, engineering, and physical hazard components of flood risk. Additionally, the study aims to develop a new modeling approach for integrating behavior, flood hazards, and engineering interventions. The hypothesis is that the interaction of policies, individual behavior, and flood mitigation measures can result in unanticipated changes to flood vulnerability that are not captured by standard engineering-based models. An agent-based model (ABM) is used to analyze the influence of flood protection measures, both structural and nonstructural, individual behavior, policies, subsidies, and the occurrence of floods and near-miss flood events on community flood risk. The ABM focuses on the following decisions and behaviors: dissemination of flood management information, installation of community flood protection, elevation of household mechanical equipment, and elevation of homes. We do not address the issue of flood insurance here, instead leaving this for future work. The approach is place based, with a case study area in Fargo, North Dakota, but is focused on generalizable insights into the roles of individual and community action in driving the evolution of flood risk.

There are two key questions that this study strives to address: (1) How does community flood risk evolve over time in light of stochastic flood outcomes, individual behavior, and community interventions? (2) What are the strengths and limitations of agent-based modeling as a tool for simulating evolving flood risk?

\section{BACKGROUND}

\subsection{Human Behavior and Flood Risk Perception}

In reviewing the relevant literature, it is clear that experience and beliefs play a significant role in individual flood mitigation behavior. In a study of perceptions of flood risk on the Red River of the North following the 1997 flood, it was found that a community that has been exposed to a natural hazard cannot be treated as a homogenous group. Responses depend on experience, background, and personal viewpoint. ${ }^{(5)}$ Siegrist and Gutscher ${ }^{(6)}$ found that flood experience results in increased perceived risk and preventative behavior. People affected by past floods are more likely to implement structural flood mitigation measures. Those without flood experience envision flood consequences differently than those with experience. Insecurity and uncertainty stay in the minds of those who have flood experience, though they do not always implement mitigation measures due to concerns about cost and effectiveness. A study by Bubeck et al. ${ }^{(7)}$ found that people who live in risk-prone areas rarely undertake mitigation measures voluntarily, and this contributes to vulnerability. In addition to experience with floods, they point out several factors that impact the adoption of individual mitigation measures, including fear or worry about flooding, knowledge about flood hazards, socioeconomic and geographical factors, deterrent factors (i.e., belief that flood mitigation is a governmental responsibility), and perceived effectiveness of mitigation measures. They find that the adoption of individual flood mitigation measures is less related to an individual's perception of the risk and more related to his or her perception of mitigation options. Risk perception is unique to the individual and is based on prior flood experience, the public's trust in expert knowledge and safety measures, misunderstanding of probabilities, trust in flood control structures, and the assumption that if the government allows you to live in an area it is safe. ${ }^{(8)}$

More generally, disaster research has shown that level of preparedness is significantly linked to individual experience with disasters. ${ }^{(9-13)}$ In particular, past events and near-misses affect risk perceptions such that the outcomes of prior events might alter perceptions of information about future events. ${ }^{(14-19)}$ One of the critical findings from this work is that there is a high degree of variability across individuals in response to repeated events. ${ }^{(14)}$ This suggests that in modeling behavioral responses to floods and flood 
protection measures, an approach is needed that can explicitly model a high degree of localized heterogeneity in behavioral responses.

A study by Koks et al. ${ }^{(20)}$ showed the value of joint assessment of hazard, exposure, and social vulnerability. Embanked areas are often low lying and densely populated, and experience low-probability, high-consequence flooding. Vulnerability characteristics have a strong spatial variation and a heterogeneous risk pattern. The study recommends including both physical and social vulnerability in risk assessment. Perceptions of risk and risk-related behaviors may amplify the social, political, and economic impact of disasters well beyond their direct consequences. Social facets of flooding have been historically overlooked in flood management. Furthermore, there are still weaknesses in the understanding of flood risk perceptions and mitigation behavior. ${ }^{(21)}$

\subsubsection{Threat and Coping Appraisal}

Flood-coping appraisal is an important factor in flood risk management behavior. Coping appraisal is the process people go through to evaluate their ability to avoid a certain risk. Threat appraisal involves perceived vulnerability (probability) and perceived severity (consequences). Coping appraisal involves response efficacy (does a person consider a protective measure to be effective), self-efficacy (does the person feel able to implement the measure), and response cost (financial, time, and emotional cost associated with implementing the measure). ${ }^{(22)}$ Studies do not find significant correlation of perceived probability with flood mitigation behavior. ${ }^{(7)}$ Threat appraisals have a small effect on mitigation behavior, whereas coping appraisals have a bigger influence. ${ }^{(23)}$ High risk perceptions need to be accompanied by coping appraisal for protective response to occur. Knowledge is not always a good predictor of mitigation behavior. ${ }^{(7)}$

\subsubsection{Flood Experience}

People without flood experience envision the consequences of a flood differently than those with experience. This is due to the concept of availability, wherein people with no flood experience have trouble envisioning and evaluating the consequences. For groups affected by floods, uncertainty, fear, shock, and helplessness were among the worst aspects of a flood. Those without experience rarely mention these aspects. Affected people are more likely to change behaviors and implement structural measures. Experience with a serious flood results in acquiring new information. People with recent flood experience are less convinced that they are well protected. However, people with flood experience may not mitigate due to doubt about effectiveness and high cost. ${ }^{(6)}$

Perceived personal risk is related to the intensity and frequency of hazard experience. This can involve hazard experience by family, neighbors, friends, and co-workers. Perceived risk is also impacted by information from public authorities and the news media. ${ }^{(24)}$ Hazard experience increases the adoption of hazard adjustments. Proximity and intrusiveness of the hazard are also relevant. ${ }^{(25)}$

An individual's subjective perception of risk influences his or her protective behavior. Most individuals do not make cost-benefit tradeoffs when deciding whether to purchase insurance, and personal experience with disasters significantly influences the demand for insurance. According to Dillon et al., ${ }^{(16)}$ when probabilities are below a certain threshold, people tend to assume a bad outcome cannot happen to them. They weight low-probability events as "noprobability" events, and perceptions of flood risk are strongly influenced by past experience. Experts pay more attention to probability whereas the general population pays more attention to the consequences. Statistical risk is just one piece of information that people consider. ${ }^{(16)}$

\subsubsection{Near-Miss Flood Events}

In general, research shows that rather than serving as warning signs and increasing risk perception, near-miss flood events are often judged as successes. Lower levels of perceived risk encourage people who have experienced near-miss events to make riskier decisions. Near-misses can lead to complacency and can lower perceived risk. People are generally more influenced by what did happen than what might have happened. ${ }^{(15)}$ A near-miss can be defined as an "event that had a nontrivial probability of ending badly, but by chance did not."(16) As noted by Dillon et al., ${ }^{(16)}$ people mistake good fortune as an indicator of resiliency, and people with near-miss information, either personal or anecdotal, are less likely to purchase flood insurance. People who escape damage by chance will make decisions consistent with the perception that a situation is less risky. Prior hits increase the likelihood of protective action while prior misses decrease the likelihood of protective action 
compared to those without near-miss information. Near-miss events discourage people from attending to risk due to some implicit Bayesian updating of probabilities. $^{(16)}$

According to Tinsley et al., ${ }^{(17)}$ near-miss events can be categorized as vulnerable or resilient. A vulnerable near-miss is where a disaster almost happened and affects perceived vulnerability. A resilient near-miss is where a disaster could have happened and affects perceived resilience; this can decrease mitigation behavior. The narrative that accompanies near-miss facts can impact reactions to hazards. If near-misses can be recognized and interpreted as disasters that almost happened, that can counteract the "near-miss effect" and encourage mitigation. Vulnerable near-misses involve a negative association and promote risk mitigation. ${ }^{(17)}$

\subsubsection{Socioeconomic Factors}

Socioeconomic factors may influence risk perception and coping perception as well as mitigation behavior. Although studies on this topic are somewhat inconsistent, ${ }^{(7)}$ a study by Bubeck et al. ${ }^{(22)}$ indicates that income has a strong positive influence on implementation of mitigation measures, whereas wishful thinking and postponement have a negative influence. This study also indicates that social environment, living in a protected area, and income increase the odds of an owner implementing a structural measure. In a study by Botzen et al., ${ }^{(26)}$ socioeconomic characteristics (including sex, age, and income) had no statistically significant effect on mitigation decisions, whereas education had a positive and significant effect. The roles of government, risk perception, and geographical characteristics were more important than socioeconomic characteristics. ${ }^{(26)}$ In another study, the following demographic factors had a positive impact on risk perception: lower education and income, female gender, and ethnic minority status. ${ }^{(24)}$

Although demographic indicators are generally unreliable predictors of implementation of mitigation measures, they have an effect on perception of hazards and of mitigation measures. ${ }^{(25)}$ Positive indicators for implementation of mitigation measures include social trust, risk perception, and social economic status (education, income). Negative indicators include psychological vulnerability (powerlessness, helplessness). According to Bubeck et al., ${ }^{(7)}$ homeownership is an important factor, since tenants have a lower demand for mitigation. Age and educa- tion level have a small or no impact on precautionary behavior. The distance to a water body has little effect on mitigation behaviors. ${ }^{(7)}$

\subsubsection{Neighbors and Friends}

According to a study by Bubeck et al., ${ }^{(22)}$ people often ignore residual risk, particularly in areas with flood defenses. Examples of neighbors or friends who have implemented a flood mitigation measure have considerable influence on precautionary behavior. If the majority of homeowners in a neighborhood have implemented a mitigation measure, it is likely that others will want to follow suit. Decisions of neighbors can provide important information value. An overlap of household and community measures does occur, but often may be due to the timing of implementation. ${ }^{(22)}$ Research shows that people can learn through their own experiences and also vicariously through others. ${ }^{(16)}$ People's mitigation behavior depends partly on neighbors' decisions and actions. ${ }^{(17)}$

\subsubsection{Household Mitigation Measures}

For the implementation of household structural mitigation measures, a study by Poussin et al. ${ }^{(23)}$ found the most important covariates to be perception of flood damage, perceived self-efficacy, perceived response cost, incentive from insurers, incentives from others, and socioeconomic factors such as age and ownership. Feeling of protection by public measures had slightly less importance. For nonstructural measures, the most important covariates were found to be perception of flood damage, perceived self-efficacy, perceived response cost, flood experience, and incentives from others. To better prepare households for flooding, the provision of information could be improved, along with improved financial incentives for structural measures. ${ }^{(23)}$ Integrated flood risk management includes both community flood protection infrastructure plus household mitigation measures. ${ }^{(22)}$

\subsection{Community Mitigation Measures}

According to Brody et al., ${ }^{(27)}$ there is a strong link between high organizational capacity and implementation of community structural and nonstructural flood mitigation measures. Local organizational capacity includes financial resources, staffing, technical expertise, communication, leadership, and 
commitment to flood protection. The ability to adjust policies in response to a flooding problem is also important. Organizational capacity is critical for reducing local flood effects. ${ }^{(27)}$ Community investments in flood mitigation are often reactive, driven by flood damage or public outrage, and not necessarily by cost-benefit analysis or utility theory. ${ }^{(28)}$

Structural flood mitigation measures, including levees, dams, and diversions, can be highly effective in mitigating flood damage. As noted by Brody et al.,(27) the limitations of structural approaches include exceedance of design capacity, resulting in significantly higher damages than if unprotected. Channels and levees can raise the river level, causing increased flood pulses and velocities downstream. The public often gets a false sense of security associated with public mitigation measures, which can encourage new development in floodplains. Additionally, structural mitigation measures often have high financial and environmental costs, with dams and other structures causing adverse environmental impacts to fish/wildlife and water quality in hydrologic systems. ${ }^{(27)}$

Lands behind levees are generally perceived as protected, and this entices new development. Levees "filter" small floods and change the perception of flood likelihood. This can encourage settlement of marginal lands. This land may be protected from flood events to a certain degree, but vulnerability to large infrequent events increases with development behind levees. For example, an area might be protected from the 100-year flood, but the increased development behind the levee could dramatically increase the losses associated with less frequent but more intense flooding (e.g., the "200-year" event). Residents in these areas may be uninformed that they are in a floodplain for these low-probability but still possible events and therefore unlikely to take any precautionary measures. ${ }^{(8)}$ Lacking knowledge about flood risk while under the protection of structural measures, people's judgments generally depend on their level of trust in risk managers. ${ }^{(29)}$

Levee systems have also resulted in increasing flood stage in some locations such as the Mississippi River. This results in average recurrence intervals for major floods that are generally much shorter than acknowledged on managed rivers. ${ }^{(3)}$ This is compounded by the "escalation effect" where development occurs behind flood protection, and then the flood protection is scaled up to protect this development. ${ }^{(28)}$ Clearly, the impact of levees on flood risk extends beyond simple flood elevation changes that are revealed by traditional models.

\subsection{Agent-Based Models}

An ABM is a simulation model that includes decision-making entities (agents) in addition to stochastic elements. ${ }^{(30-32)}$ The agents are autonomous, spatially explicit, and heterogeneous, and can interact with each other and their environment. They can experience stochastic elements such as flooding events. Agents in an ABM are active and have learning rules that represent how they incorporate new information such as events (e.g., floods) occurring in their environment as well as from messages from other agents. They also have decision rules that specify the actions they can choose and how they choose among their possible actions. Each agent can have distinct characteristics, behavioral rules, and history. An ABM allows simulation of how the behavior of individuals impacts other individuals and a community over time. Although ABMs are used to explain, rather than predict, they can be used to simulate the emergence of system-level properties. ${ }^{(28,33,34)}$

ABMs have been widely used to examine situations in which individual behavior is an important driver of collective outcomes in ways that cannot be easily modeled by more aggregate models such as system dynamics models. Examples of ABM applications of this sort include models of civil violence, ${ }^{(35)}$ land-use change, ${ }^{(31,36)}$ agricultural decision making at the farm scale and its impacts on water quality, ${ }^{(37)}$ and individual-level responses to water contamination events and the collective impacts of these individual decisions. ${ }^{(38)}$ ABMs have been used to examine coastal flooding by Dawson et al., ${ }^{(39)}$ with a focus on real-time management of a coastal flooding event. Our study focuses on the longer time horizon societal changes (e.g., land-use change and household-level mitigation decisions) that impact the evolution of flood risk over time.

\section{METHODS AND DATA}

\subsection{Overview}

In our ABM, the agents are households, modeled as land parcels. An annual maximum flood occurs in each year of the 50-year simulation period, and flood risk metrics are recorded annually. The 
agents can take individual action and can also influence community action. Each agent makes an annual decision about flood risk management actions, as does the community. Flood risk changes over time based on stochastic flood outcomes, individual action, and community action.

As illustrated in Fig. 1, the model has three main simulation steps. In the first step, an annual flood elevation is simulated, and damage and population at risk are tallied. In the second step, each agent may take action based on risk perception, coping perception, and calculated utility. Potential actions include doing nothing, complaining to the community (requesting community action), elevating mechanical equipment, or elevating the home. In the third step, the community can take action. Actions include doing nothing, putting out an information campaign, or undertaking a structural mitigation project (simulated as a levee). These simulation steps are repeated for each year of the 50-year simulation. The inputs and modeling process for each of the steps are explained in further detail below.

In order to better understand several key components of the ABM and their influence on the results, four versions of ABM simulations were run, each with variations in decision rules. The first was a base version (Base) wherein agents follow the basic decision rules, but are not able to move in or out, and are not influenced by the flood outcomes or mitigation behavior of their neighbors. In the second version (Land Use or LU), agents may move out of the area if their risk perception reaches a high level, and vacant parcels may be occupied. In the third version (Neighbor or NB), agents may not move in or out of the study area, but are influenced by the flood outcomes and mitigation behavior of their neighbors. For purposes of this study, and due to the relatively small case study area, all agents within the study area are considered neighbors to each other. The fourth version is a combined Land Use and Neighbor simulation (LU-NB), where agents may move in or out of the study area, and are influenced by the flood outcomes and mitigation behavior of the other agents.

Five hundred replications were run for each version, and results were recorded. Five hundred replications were determined to be an adequate number based on convergence calculations ${ }^{(40)}$ on the average damage in the first five simulation years and total damage over the entire simulation period. Five hundred simulations provide $90 \%$ confidence with a relative error of $10 \%$, based on the results of 50 initial simulation runs. Equation (1) shows the convergence calculation used.

$$
n_{r}^{*}(\gamma)=\min \left\{i \geq n: \frac{t_{i-1,1-\propto / 2} \sqrt{S^{2}(n) / i}}{|\bar{X}(n)|} \leq \gamma^{\prime}\right\},
$$

where $n_{r}^{*}(\gamma)$ is the number of simulations required for convergence, $n$ is the number of replications for convergence calculation, $S^{2}(n)$ is the variance of the mean for $n$ replications, $\bar{X}(n)$ is the mean damage based on $n$ replications, and $\gamma$ ' is the adjusted relative error $=\gamma /(1+\gamma)$.

\subsection{Case Study Location}

Because flood risk is very location centric, this study uses a case study approach. The city of Fargo, North Dakota, was chosen as the case study location. Fargo is situated along the Red River of the North and is prone to regular flooding. An area of the city located adjacent to the Red River, consisting of 2,124 land parcels, was selected for the study. Extensive GIS data for this area were obtained from the City of Fargo. The case study location is illustrated in Fig. 2.

\subsection{Flood Elevation}

In the Base version, the flood elevations are sampled from a data set that was generated using peak annual flood elevations from U.S. Geological Survey (USGS) gauge 05054000 (Red River of the North, Fargo), years 1942-2013. This stream gauge lies close to the midpoint of the river within the study area. Data were available for this gauge from years 1902 to 2013. However, a study by Villarini et al. ${ }^{(41)}$ indicates that there was a change in the data set starting in year 1942. This is also evident from the parameter codes in the data set, wherein the qualifying code "Discharge affected by Regulation or Diversion" was applied starting in year 1942. Therefore, only data from years 1942 to 2013 were included in the study, for a total of 72 years of record.

A weibull distribution was fit to the data set, and the resulting estimate of the 100-year (0.01 annual chance of exceedance) flood elevation was 902.5 feet, which is comparable to FEMA's 100-year flood elevation for this location (902.1 feet). The maximum flood elevation in the data set is 903.5 feet. In order to allow for the evaluation of impacts of a greater magnitude flood in the study area, it was necessary to add 


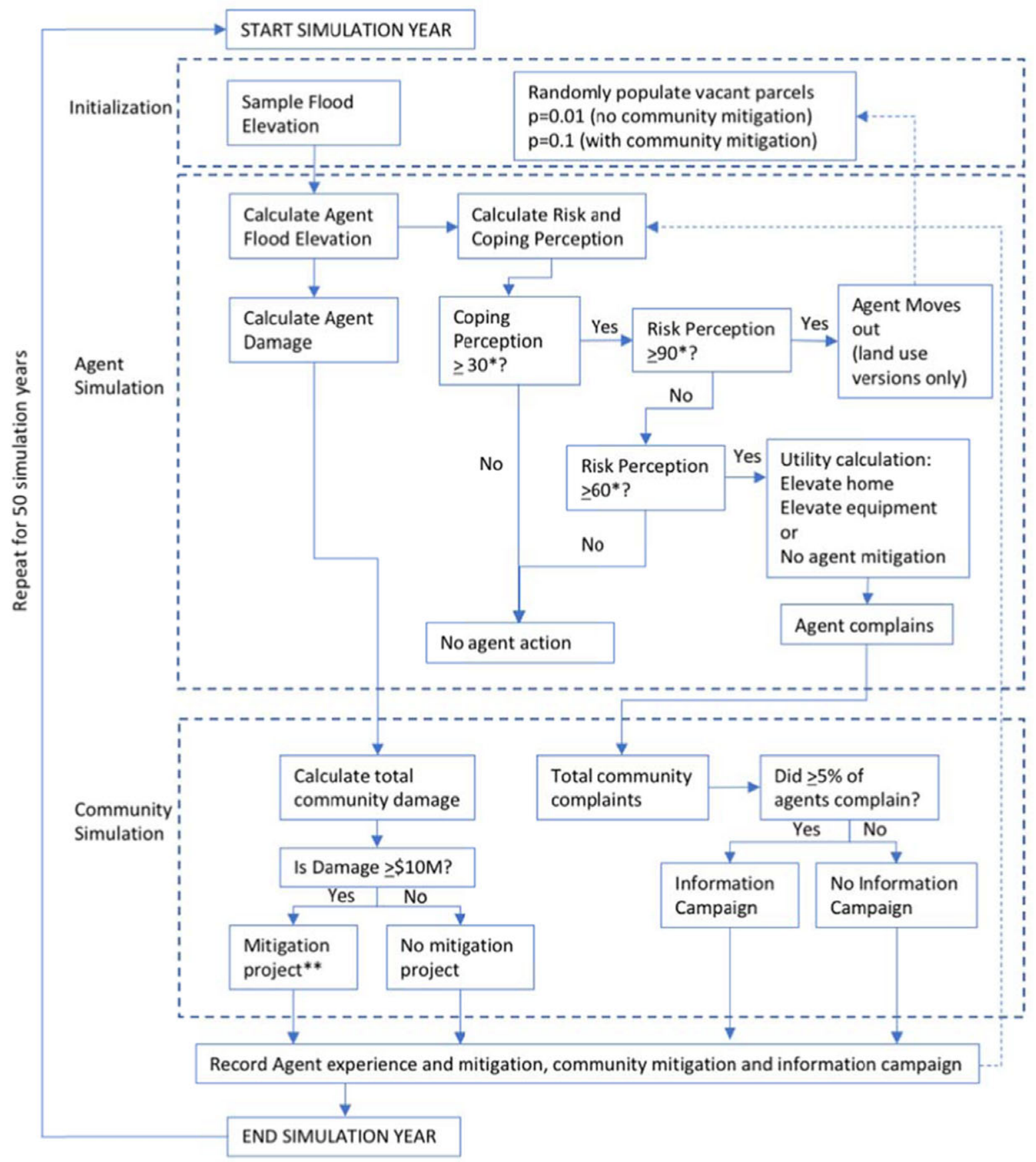

*Coping and Risk Perception thresholds adjusted by a factor of 0.8-1.2 for each agent for heterogeneity.

**Mitigation Elevation= maximum of FEMA 100 -year elevation +2 ' freeboard or highest flood elevation +1 ' freeboard

Fig. 1. Model simulation flowchart. 


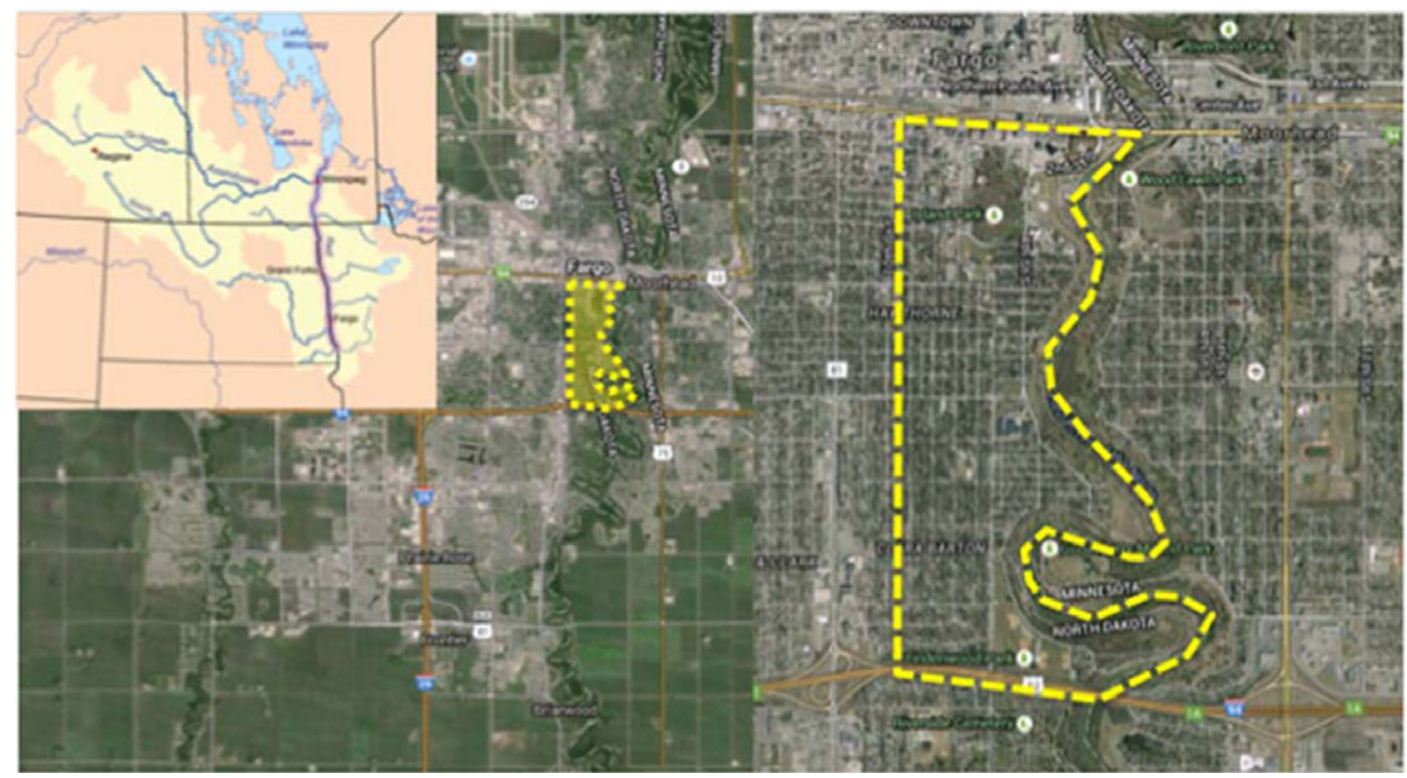

Fig. 2. Map of case study location.

a higher flood elevation to the data set. A 500-year (0.002 annual chance) flood elevation was generated from the weibull distribution, with an elevation of 905.1 feet. To generate approximately 500 years of record, the data set was replicated seven times $(72 \times$ $7=504)$. Then the 500-year elevation was added to the data set, for a total of 505 flood elevation data points to sample from in the model. This was chosen rather than generating a fully synthetic data set, so that the flood elevation sample set would mimic realworld values.

For scenarios involving community mitigation, the flood data set was altered to represent mitigation. Mitigation was simulated as a levee, and it was assumed that the levee would not fail during the length of the simulation period. Therefore, once community mitigation occurs, the flood elevation set is adjusted by replacing all data points below the mitigation elevation with zero flood elevation.

\subsection{Agent Behavior}

In each year, risk perception and coping perception values are calculated for each agent. If the risk perception and coping perception exceed specified thresholds, the agent will consider taking action to reduce flood risk. The risk perception and coping perception are based on factors identified through the literature review.
A number of factors are included in the calculation of risk perception: prior flood experience, ${ }^{(6,8,42)}$ prior near-miss experience, ${ }^{(15,16)}$ prior community mitigation, ${ }^{(8,21,22)}$ prior agent mitigation, ${ }^{(22)}$ and information. ${ }^{(23)}$ For the neighbor versions, neighbor flood experience and neighbor near-miss experience are also included. ${ }^{(16,17)}$ Due to the small size of the study area, all agents are treated as neighbors to each other. These factors are presented in Table I. The value of each factor is multiplied by a beta value and summed to generate a total risk perception value, as shown in Equation (2). The beta values are positive or negative depending on whether a factor tends to increase or decrease perceived risk. Beta values were chosen to reflect both the magnitude of the factors and the relative weight of the factors. While the literature is explicit qualitatively about important factors that influence flood risk perception, quantitative information is limited. For purposes of this study, the weights were set based on implied importance in the literature, on professional judgment, and through trials of possible factor values to observe their impact on the calculated risk and coping perception. Flood experience was given double the weight of near-miss experience. Community mitigation, agent mitigation, and information were given equivalent weights. Agent flood and near-miss experiences were given higher weights than neighbor experiences.

$$
\text { Perceived Risk }=\Sigma(\text { factor } \mathrm{x} \text { beta })
$$


Table I. Risk Perception Factors

\begin{tabular}{|c|c|c|c|}
\hline Factor & Description & Formula & Beta \\
\hline Flood Experience & $\begin{array}{l}\text { Has the agent experienced flooding in } \\
\text { previous years? }\end{array}$ & Number of floods/number of years & 200 \\
\hline Near-Miss Experience & $\begin{array}{l}\text { Has the agent experienced near-miss } \\
\text { events in previous years? }\end{array}$ & $\begin{array}{l}\text { Number of near-miss events/number of } \\
\text { years }\end{array}$ & -100 \\
\hline Community Mitigation & $\begin{array}{l}\text { Has the community previously } \\
\text { completed mitigation? }\end{array}$ & Yes $(1)$ or No $(0)$ & -20 \\
\hline Agent Mitigation & $\begin{array}{l}\text { Has the agent previously completed } \\
\text { mitigation? }\end{array}$ & Yes (1) or No (0) & -20 \\
\hline Information & $\begin{array}{l}\text { Did the community disseminate } \\
\text { information in the previous year? }\end{array}$ & Yes $(1)$ or No $(0)$ & 20 \\
\hline $\begin{array}{l}\text { Neighbor Flood } \\
\text { Experience* }\end{array}$ & $\begin{array}{l}\text { Have the agent's neighbors experienced } \\
\text { flooding in previous years? }\end{array}$ & $\begin{array}{l}\text { Number of agent floods/(number of } \\
\text { years } \times \text { total number of agents) }\end{array}$ & 1000 \\
\hline $\begin{array}{l}\text { Neighbor Near-Miss } \\
\text { Experience* }\end{array}$ & $\begin{array}{c}\text { Have the agent's neighbors experienced } \\
\text { near-miss events in previous years? }\end{array}$ & $\begin{array}{l}\text { Number of agent near-misses/(number of } \\
\text { years } \times \text { total number of agents }\end{array}$ & -500 \\
\hline
\end{tabular}

*Neighbor versions only.

Table II. Coping Perception Factors

\begin{tabular}{lll}
\hline Factor & \multicolumn{1}{c}{ Description } & Formula \\
\hline $\begin{array}{ll}\text { Base Coping Perception } \\
\text { Home Value }\end{array}$ & Random value assigned to each agent & Random value between 0 and 20 \\
& Value assigned based on property value & $<\$ 100,000: 5$ \\
& & $\$ 100,000-\$ 125,000: 10$ \\
& & $\$ 125,000-\$ 175,000: 15$ \\
Prior Agent Mitigation & Has agent previously completed mitigation? & $>175,000: 20$ \\
& & Yes $(20)$ \\
Information & Did the community disseminate information in the & No $(0)$ \\
Neighbor Mitigation ${ }^{*}$ & previous year? & Yes $(20)$ \\
& How many of the agent's neighbors have completed & $<0$ \\
& mitigation? & $1-5: 5$ \\
& & $6-10: 10$ \\
& & $11-20: 15$ \\
\hline
\end{tabular}

${ }^{*}$ Neighbor versions only.

The following factor values would result in equivalent magnitude impacts $( \pm 20)$ on flood risk perception: if an agent experiences one flood event in 10 years; two near-miss events in 10 years; community mitigation project; agent mitigation project; community information campaign; $20 \%$ of agents experiencing a flood in 10 years, or $40 \%$ of agents experiencing a near-miss event in 10 years.

The risk tolerance threshold-the risk perception level at or above which an agent will consider taking action-was set at 60 based on the authors' professional judgment. Possible values of the risk perception factors were analyzed to identify the likely threshold at which agents would perceive the risk high enough to consider mitigation action. To simulate agent heterogeneity in risk tolerance, each agent was randomly assigned a risk tolerance adjustment factor between 0.8 and 1.2. The risk threshold was multiplied by this factor so that the threshold was specific to each agent's tolerance value.

In addition to the risk threshold for agent action, we set in the LU and LU-NB versions a higher risk threshold at which agents will move out and the parcel becomes vacant. This threshold is set at 90 and is also adjusted by the risk tolerance factor. At the start of each simulation year, there is a probability that each vacant parcel will be occupied. If there is no community mitigation in place, the probability that a vacant parcel will be occupied in a given year is 0.01 . If community mitigation is in place, the probability that a vacant parcel will be occupied is 0.1 .

Coping perception is calculated similarly, as shown in Equation (3). Factors are described in Table II and include a base value that is randomly 
(a)

Average annual damage (\$)

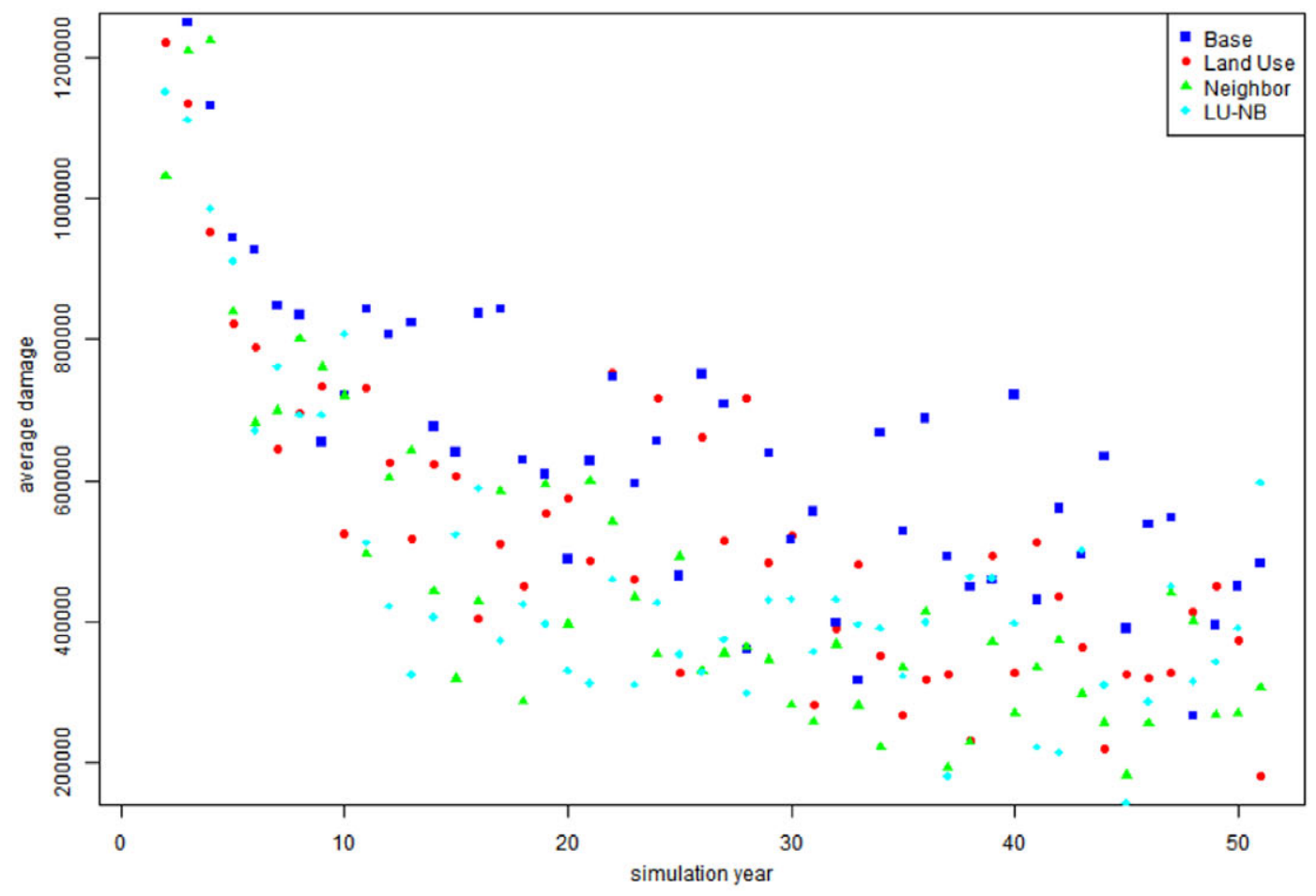

(b)

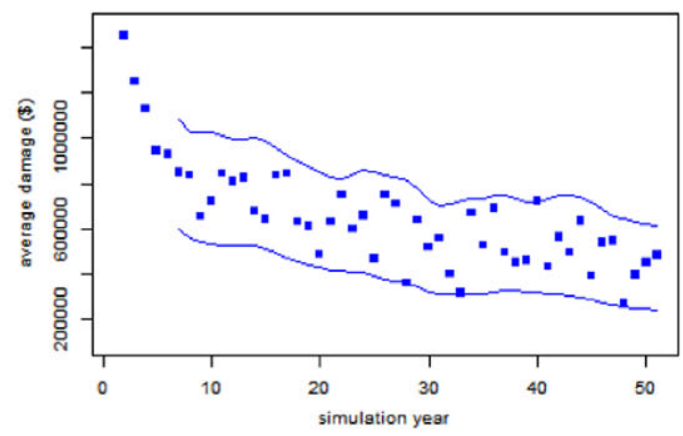

Average Damage, NB (w/ $90 \% \mathrm{Cl})$

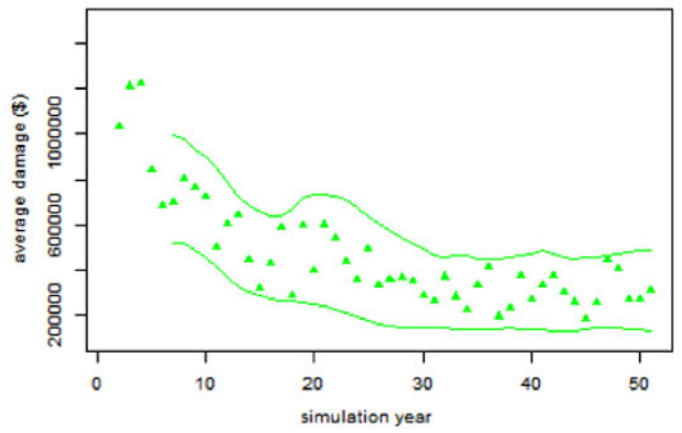

Average Damage, LU (w/90\% CI)

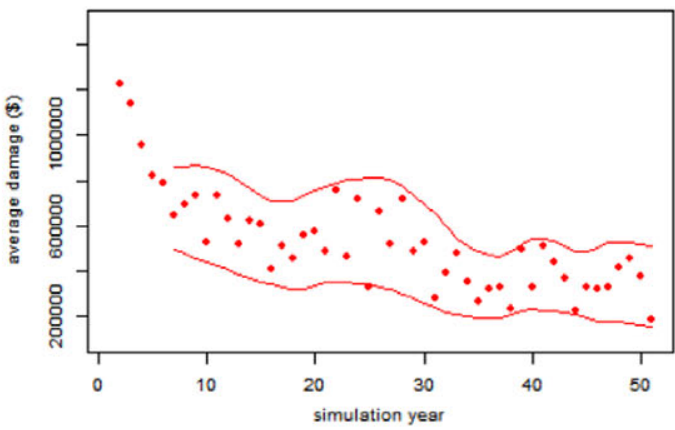

Average Damage, LU-NB (w/ 90\% Cl)

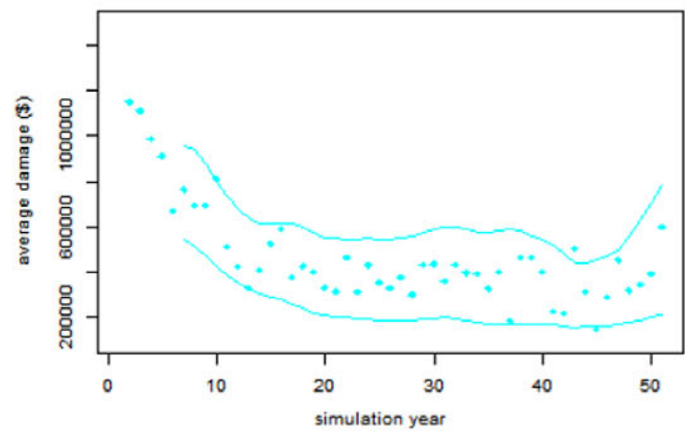

Fig. 3. (a) Average annual damage. (b) Average annual damage. 
(a)

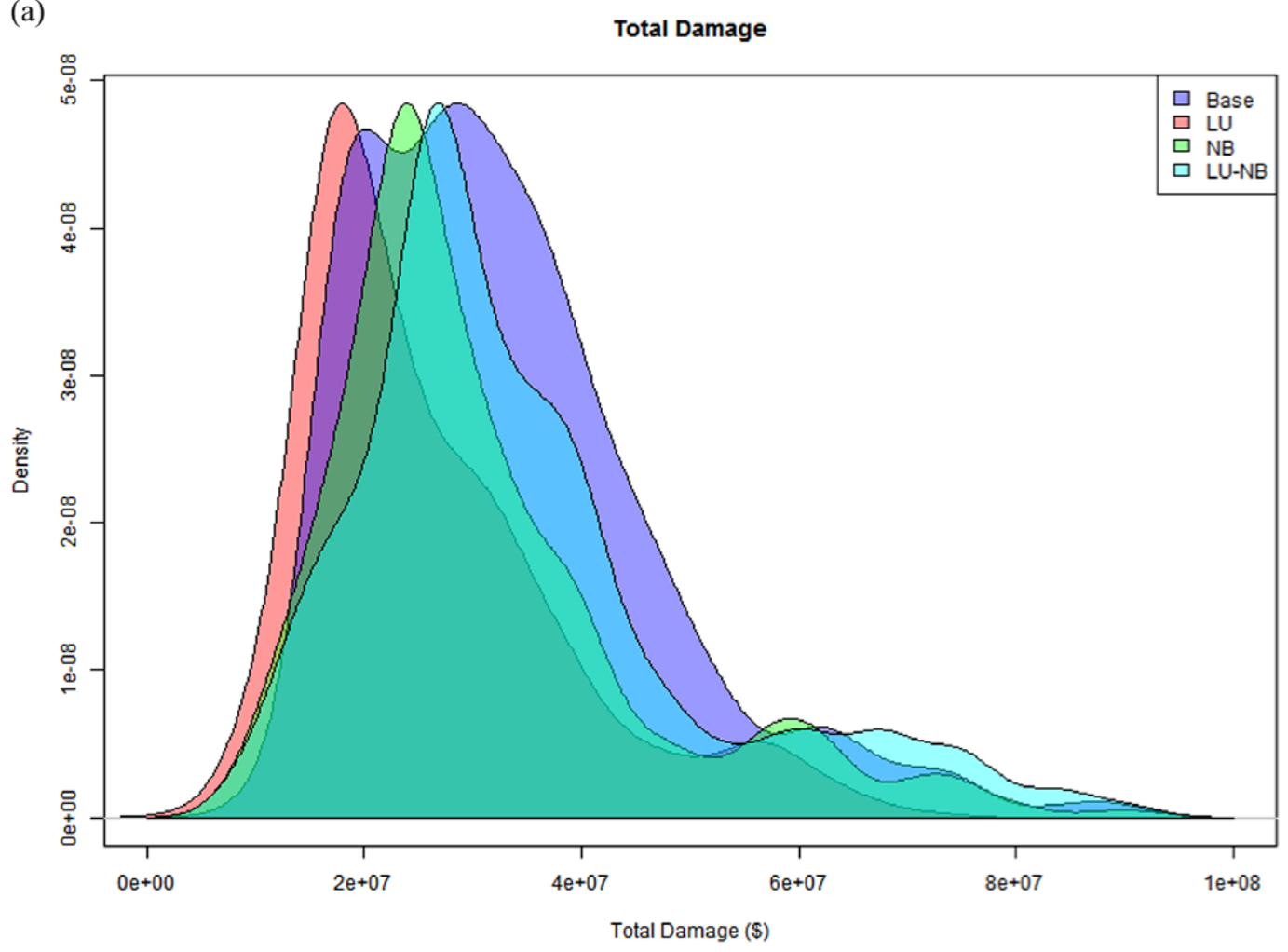

(b)

Total Damage per Capita

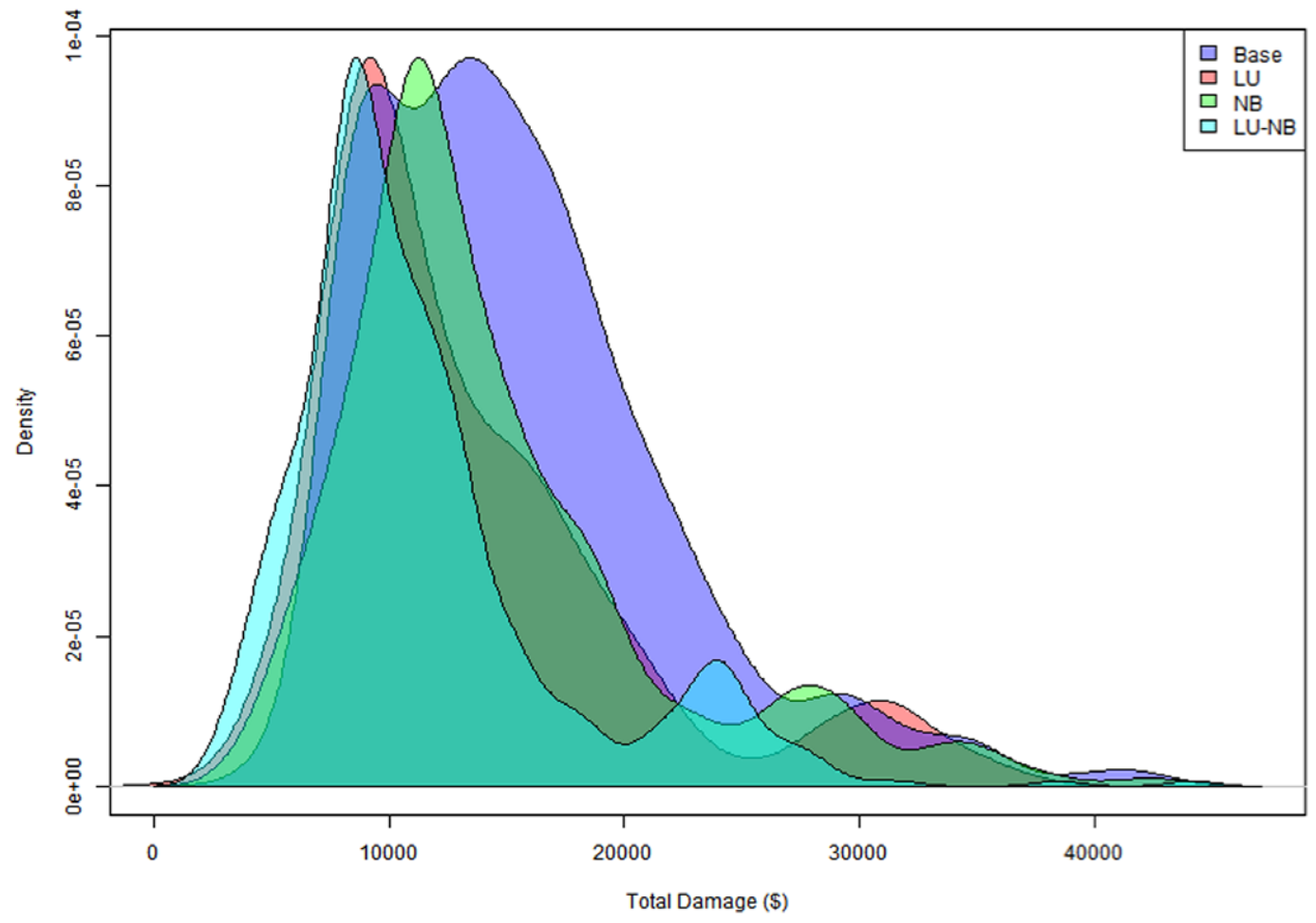

Fig. 4. (a) Density plot of total damage. (b) Density plot of total per capita damage. 


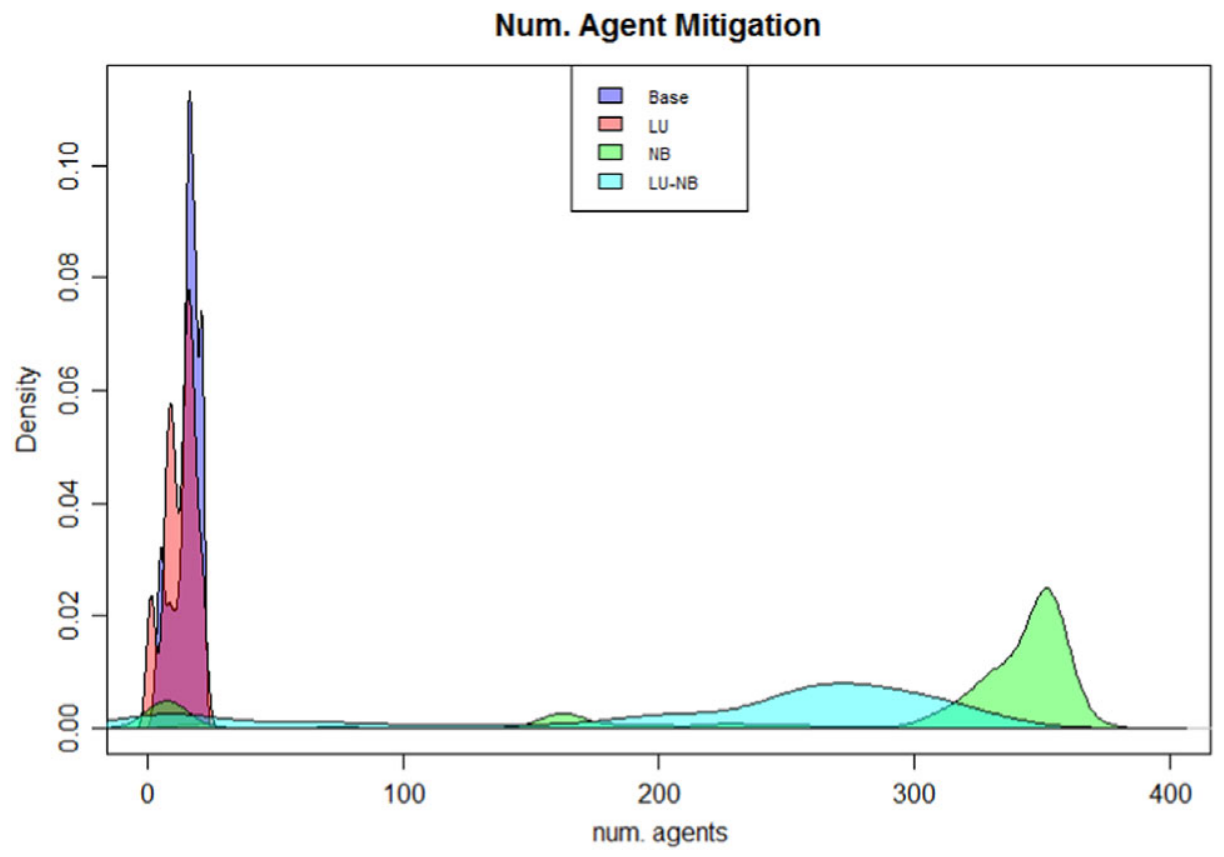

Fig. 5. Density plot of agent mitigation.

assigned to each agent, home value as a proxy for socioeconomic factors, ${ }^{(22,23,42)}$ prior agent mitigation, ${ }^{(22)}$ and information. ${ }^{(8,23)}$ The $\mathrm{NB}$ and LU-NB versions also include prior neighbor mitigation. ${ }^{(17,22)}$ Each of these factors are equally weighted and are assigned a value from 0 to 20 . Home value is intended to be a proxy for socioeconomic factors that impact coping perception. The maximum possible coping perception value is 100 . The coping threshold is set at 30 , based on an analysis of possible values and the authors' professional judgment. Implications of variations in risk and coping thresholds were tested through extensive sensitivity analysis (see supplemental online material for details).

$$
\text { Perceived Coping }=\Sigma(\text { factor })
$$

Actions include complaining to the community, elevating mechanical equipment, and elevating the house. Each time the coping and risk perceptions meet the specified threshold, the agent complains to the community (requests community action). Additionally, when both the coping and risk perceptions meet the specified thresholds, the agent considers mitigation. The choices of mitigation actions include doing nothing, elevating mechanical equipment, or elevating the whole house. A utility function is run and the agent's decision is based on the lowest cost option using the utility function.

\subsection{Community Action}

As stated above, if an agent's risk and coping perceptions meet or exceed the threshold values in a given year, he or she complains to the community. If the number of complaints in a given year equals $5 \%$ or more of the agents in the community, the community will undertake an information campaign. The U.S. Army Corps of Engineers provides flood risk and mitigation information to communities on a regular basis. However, communities do not always embark on specific flood risk information campaigns unless prompted to do so. Agents who receive information from the community are more likely to perceive a higher risk of flooding and to undertake mitigation. ${ }^{(8,24)}$

The model assumes that if the total community flood damage exceeds $\$ 10$ million in a given year, the community will complete a flood mitigation project. In this study, the mitigation project is modeled as a flood barrier/levee project. A depth-damage curve was generated for the case study location, and the $\$ 10$ million threshold was selected based on the point on the curve in which damage begins to increase somewhat sharply. We assumed that this corresponds 
Total Damage (Base)

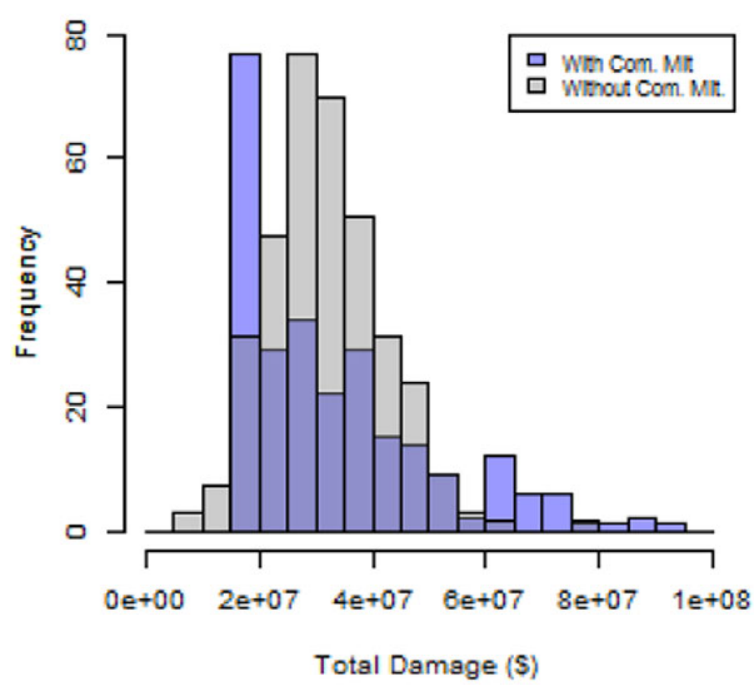

Total Damage (NB)

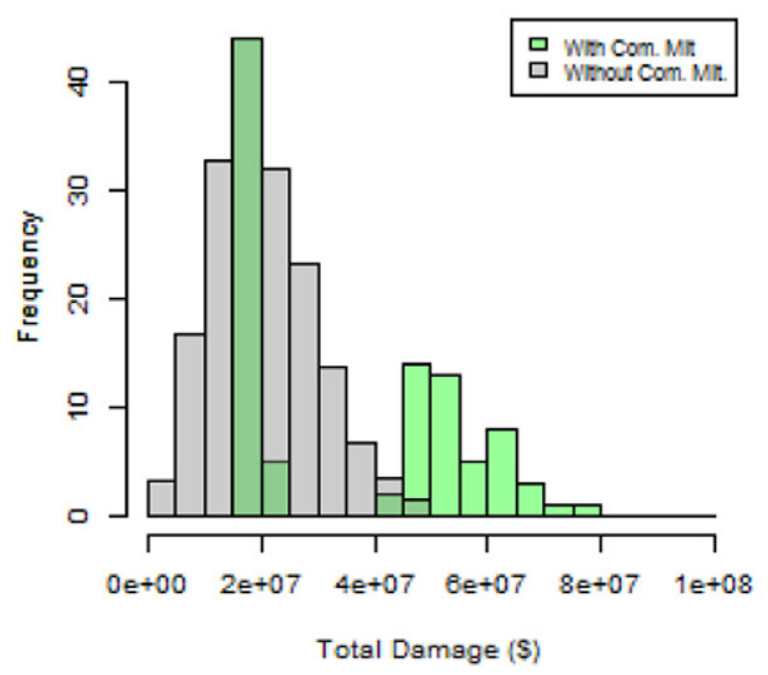

Fig. 6. Damage with and without community mitigation.

to the flood elevation where damage is significant enough to warrant community action.

\section{RESULTS}

\subsection{How Does Flood Risk Change Over Time?}

Figs. 3a and 3b illustrate the average annual damage (average of 500 simulations) for each of the versions over the 50-year simulation period. Average annual damage declines over time due to the influences of agent mitigation, community interven-
Total Damage (LU)

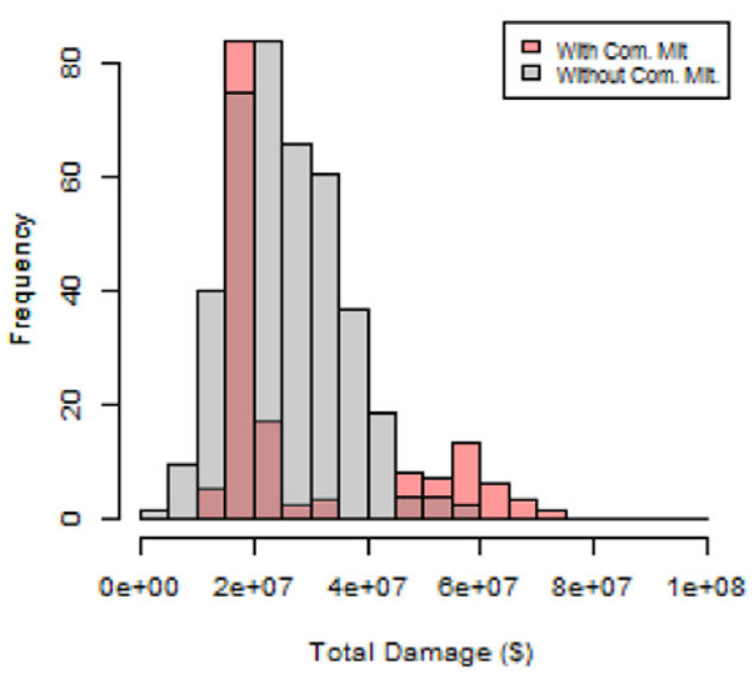

Total Damage (LUNB)

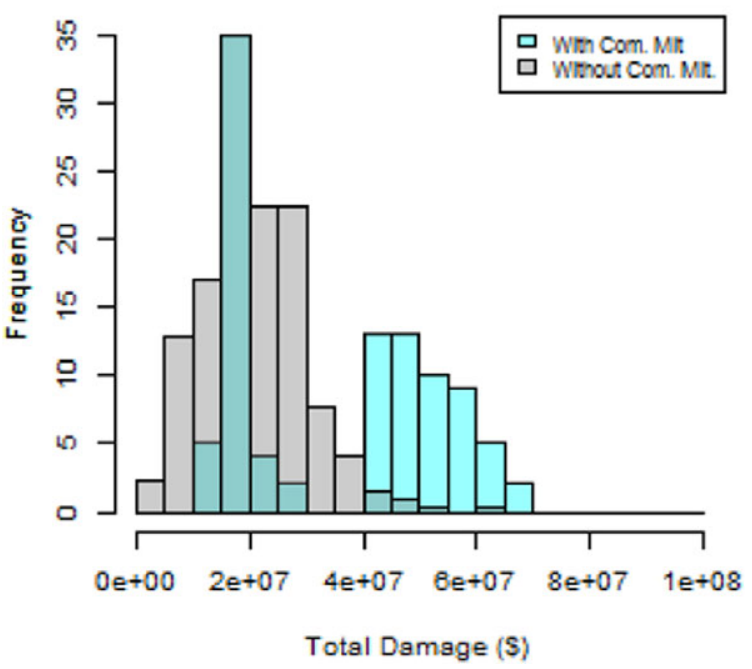

tion, and movement in and out of at-risk areas. The Base version generally has the highest annual average damages. The Neighbor and LU-NB versions generally have the lowest annual average damages, and the LU version seems to exhibit the greatest fluctuation in annual damage.

In the LU version, agents can move in and out of the study area. Damages for this version decrease along with the other versions initially, but then increase for some of the middle years due to agents moving into the study area. This version has slightly wider $90 \%$ confidence bounds in the middle years 
Table III. Summary of Damage Before and After Community Mitigation

\begin{tabular}{lccccc}
\hline Version & $\begin{array}{c}\text { Avg. Year of } \\
\text { Community } \\
\text { Mitigation }\end{array}$ & $\begin{array}{c}\text { Avg. Annual Damage } \\
\text { Before Community } \\
\text { Mitigation }\end{array}$ & $\begin{array}{c}\text { Avg. Annual Damage } \\
\text { After Community } \\
\text { Mitigation }\end{array}$ & $\begin{array}{c}\text { Max. Annual Damage } \\
\text { Before Community } \\
\text { Mitigation }\end{array}$ & $\begin{array}{c}\text { Max. Annual Damage } \\
\text { After Community } \\
\text { Mitigation }\end{array}$ \\
\hline Base & 22.7 & $\$ 3,678,384$ & $\$ 72,242$ & $\$ 88,636,114$ & $\$ 44,631,991$ \\
LU & 18.7 & $\$ 3,431,480$ & $\$ 30,407$ & $\$ 72,062,866$ & $\$ 40,593,226$ \\
NB & 16.1 & $\$ 4,452,000$ & $\$ 41,990$ & $\$ 77,672,006$ & $\$ 45,970,167$ \\
LU-NB & 18.6 & $\$ 4,158,000$ & $\$ 36,710$ & $\$ 67,925,311$ & $\$ 41,196,200$ \\
\hline
\end{tabular}

Table IV. Damage and Agent Mitigation With and Without Community Mitigation $(\mathrm{CM})$

\begin{tabular}{lccccc}
\hline & \multicolumn{2}{c}{ Avg. Total Damage } & & \multicolumn{2}{c}{ Avg. Agent Mitigation } \\
\cline { 2 - 3 } \cline { 6 - 6 } & With CM & Without CM & & With CM & Without CM \\
\hline Base & $\$ 32.48 \mathrm{M}$ & $\$ 43.6 \mathrm{M}$ & & 15 & 41 \\
LU & $\$ 26.14 \mathrm{M}$ & $\$ 28.8 \mathrm{M}$ & & 12 & 22 \\
NB & $\$ 23.17 \mathrm{M}$ & $\$ 25.8 \mathrm{M}$ & & 292 & 315 \\
LU-NB & $\$ 23.40 \mathrm{M}$ & $\$ 24.6 \mathrm{M}$ & & 219 & 233 \\
\hline
\end{tabular}

due to variations in movement in and out of the study area. For instance, in year 25, the confidence bounds for the LU version span a damage range of about $\$ 640,000$ versus $\$ 520,000$ for the Base version, $\$ 380,000$ for the NB version, and $\$ 360,000$ for the LU-NB version.

The neighbor versions generally have lower average annual damage than the Base or LU versions. Neighbor flood events tend to increase an agent's perceived risk, whereas neighbor near-miss events tend to decrease an agent's perceived risk. Coping perception is positively affected by neighbor mitigation, which leads to higher numbers of agents mitigating and moving out of the study area. The LU-NB results tend to fall in between the results of the LU and the NB versions.

Fig. 4a shows a density plot of the total damage for each of the four versions, based on 500 simulations each. In evaluating the density plot, it appears that the LU simulations tend to have lower total damages than the other simulations, followed by the NB and the LU-NB simulations. The lower total damage for the LU version seems to be driven by lower average annual damages in the early years of the simulation and increasing vacancy rates. The Base simulations are more likely to have higher total damages.

Total damage evaluated on a per capita basis (Fig. 4b) differs from the total damage results in several ways. In reviewing total damage, the LU version tends to have the lowest damage, followed by the NB version, and then the LU-NB version. However, on a per capita basis, the LU-NB version tends to have the lowest total damage, followed very closely by the LU version, and then the NB version. In the landuse simulations, the agents at highest risk tend to be the ones who move out, resulting in lower per capita damages. Typical values of total per capita damages for the Base version span a wider range than the other versions, as do typical values of total damages for the Base version. In some runs, total per capita damages are lower for the Base version than for the NB version. This is likely due to increased agent mitigation in the NB version, which can lead to decreased community mitigation. In general, total per capita damage for the NB version is less than that for the Base version. Decisionmakers may want to consider per capita damages instead of total damages if they are interested in keeping a community intact and vibrant versus solely minimizing flood risk. The per capita damage is also more relevant for homeownerlevel insurance claims. Our model accounts for risk only within the study area, and does not consider any risk incurred by agents who move out of the study area.

As shown in Fig. 5, the Base and Land Use versions have low numbers of agents mitigating in all simulations, ranging from around 0 to 30 agents. The NB and LU-NB versions have more agents mitigating, with many NB simulations having 300 to 400 agents mitigating and many LU-NB simulations having 200 to 300 agents mitigating. More agents mitigate in the neighbor versions due to increased coping perceptions associated with other agents mitigating. The LU-NB version has less agent mitigation than the NB version due to agents choosing to move out and, therefore, not mitigating.

\subsection{How Does Community Action Affect Risk?}

Fig. 6 shows the total damage for runs where community mitigation occurred and for runs where 
Property Value

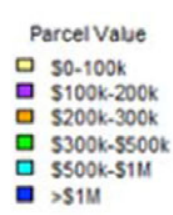

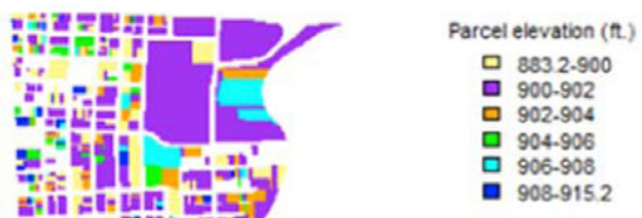

\section{Parcel Elevation}

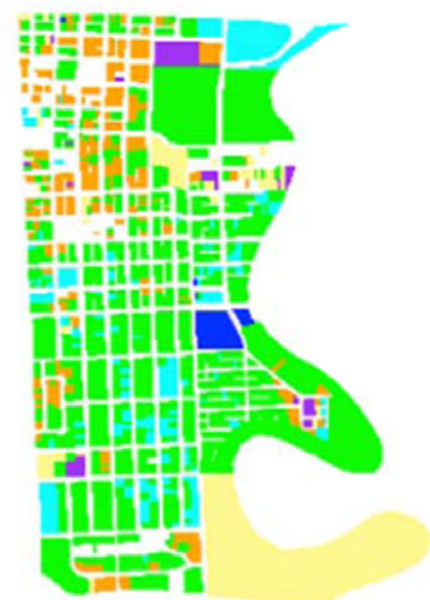

Fig. 7. Maps of parcel properties.

Total Damage (Base)

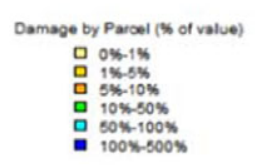

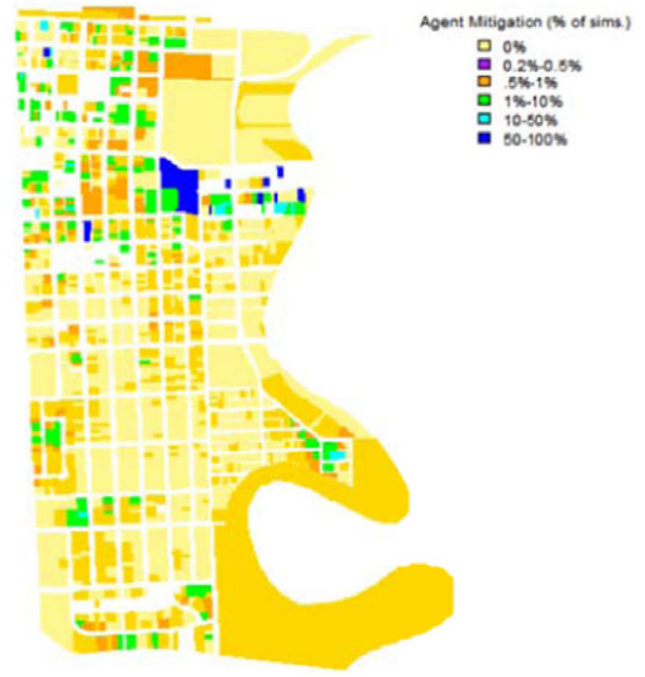

Agent Mitigation (Base)

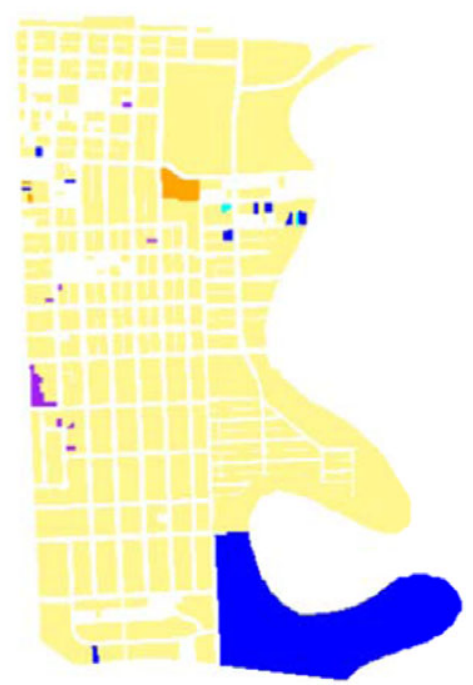

Fig. 8. Maps of Base version results.

it did not occur for each of the four versions. These histograms show that the runs with community mitigation generally have lower damages than those without community mitigation. However, for all four of the versions, the runs with the highest damages are those with community mitigation. In evaluating this figure, it was unclear whether this was because community mitigation was triggered by damaging flood events, or because once community mitigation was installed, risk perception declined and agents tended not to undertake individual mitigation action. To further explore the reasoning, the total damage before and after mitigation was tabulated and is included in Table III. In reviewing this table, it is clear that average annual damage is much lower after community mitigation than before mitigation, as should be expected since there is no damage in most years after mitigation. The maximum damage in any individual year before community mitigation is typically higher than the maximum annual 
Total Damage (LU)

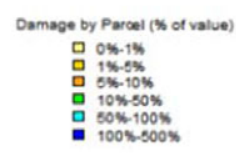

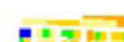

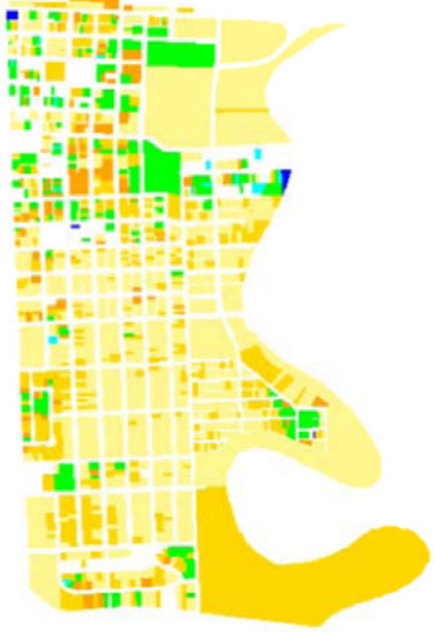

Agent Mitigation (LU)

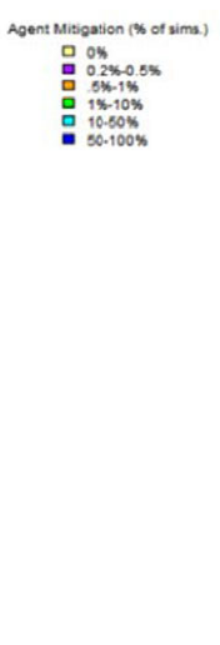

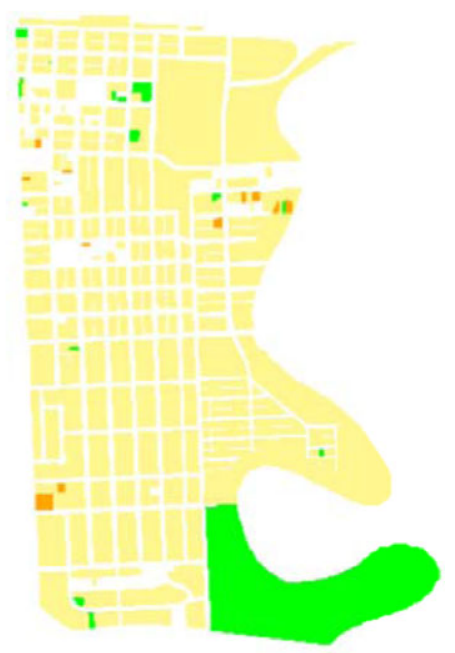

Year 51 Vacancy (LU)
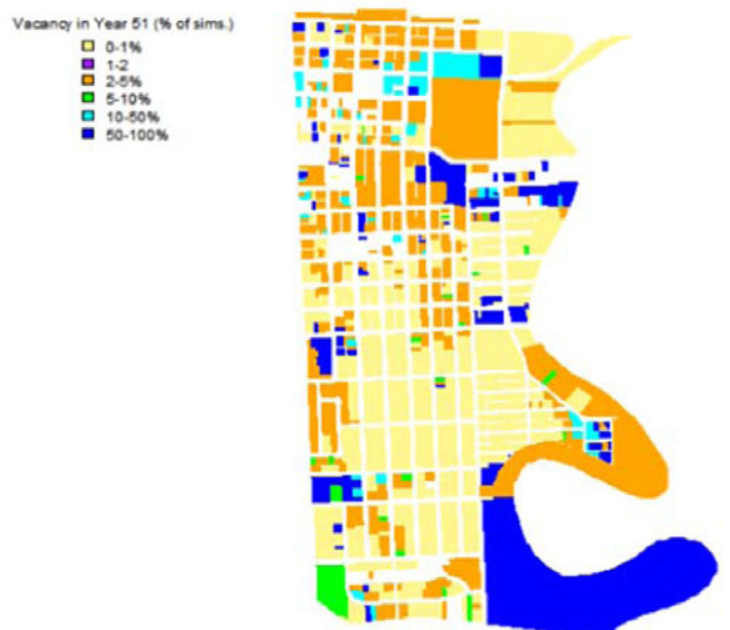

Fig. 9. Maps of Land Use version results.

individual year damage after community mitigation for each of the four versions when evaluating the simulations on the whole. However, for some individual simulations, the highest damage year occurs after community mitigation is in place. These results indicate that, in general, damage is significantly reduced after community mitigation. In some instances, high elevation floods occur after mitigation and exceed the mitigation height, resulting in very high damages.

In order to further understand the influence of community mitigation, the four versions were run with the possibility of community mitigation disabled in the simulation. Table IV shows average total results with and without the potential for community mitigation. For all of the versions, the average total damage is higher without the potential for community mitigation. The difference is much greater for the Base version, where agents do not have the option to move out, and there is no neighbor influence on agent mitigation. The average number of agents mitigating is higher without the potential for community mitigation, which may offset some of the damage associated with the lack of community mitigation. Although the costs of community mitigation are not evaluated in this study, the difference in average total damage with and without community mitigation may not be substantial enough in some cases to compensate for the cost of a community mitigation project. 

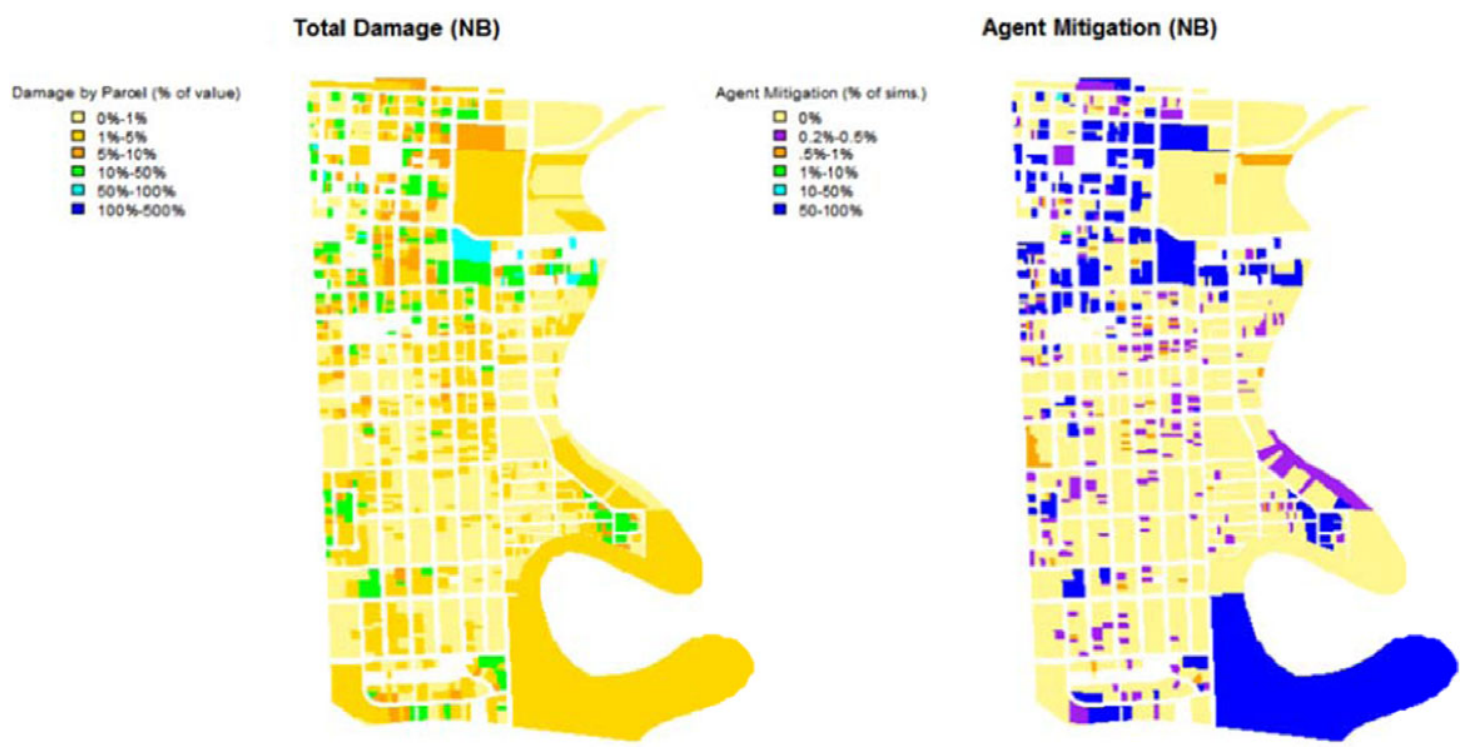

Fig. 10. Maps of Neighbor version results.

\subsection{How Does Individual Behavior Affect Risk?}

The maps in Fig. 7 illustrate property value and parcel elevation for each agent. Figs. 8-11 show total damage and agent mitigation for each individual agent, as well as vacancy in the final simulation year (year 51) for the land use versions. The total damage is presented as a percentage of property value (total damage divided by property value), and agent mitigation is shown as the percentage of simulations where the agent mitigated. Damage and mitigation do occur in areas that are not adjacent to the river, and it is assumed that all areas are hydraulically connected, based on the prevalence of low-lying roads in the study area.

Agent mitigation is very limited in the Base and LU versions, and much more prevalent in the NB and LU-NB versions. This is due to the influence of neighbors on agents, particularly the increase in coping perception associated with neighbors taking mitigation action. In evaluating the plots, it is clear that lower-elevation agents install mitigation measures more frequently than higher-elevation agents. Much of the agent mitigation is clustered in the northwest portion of the study area, where the parcels tend to have elevations in the range of 902 to 904 feet, and in lower lying areas along the river. The same agents tend to mitigate in each of the four versions due to agent characteristics.

Total damage is generally highest in low-lying parts of the study area, including the northwest area, portions along the river, and some areas along the western and southern borders of the study area. The central to south central portion of the study area seems to have the lowest total percent damage. This area also has higher property values, in general, than other portions of the study area, and some parcels within this area have higher elevations.

In general, the vacancy rate in the final simulation year is highest in portions of the study area that had higher damage values, as described above. In studying results for individual agents, some with very high vacancy percentages have very low damage percentages. This indicates that agents act preemptively based on high risk and coping perceptions. For instance, the agent located in the southwest corner of the study area, with moderate to high property value and elevation, has a vacancy rate in the $5-10 \%$ range for the LU version and $10-50 \%$ in the LU-NB version, with damages in the $0-1 \%$ range for each.

Initially, $5 \%$ of the study area is vacant. Figs. $12 \mathrm{a}$ and $12 \mathrm{~b}$ illustrate how vacancy changes over time in the Land Use version. In the LU version, vacancy generally increases slightly from the initial rates in the middle and late years of the study, with certain simulation runs having much higher vacancy rates than the rest. In the LU-NB runs, the increase in vacancy rates is more pronounced. In many runs, vacancy increases in the middle years, and then decreases slightly in the late years. 
Total Damage (LU-NB)

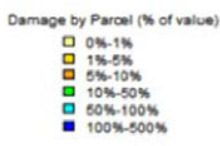

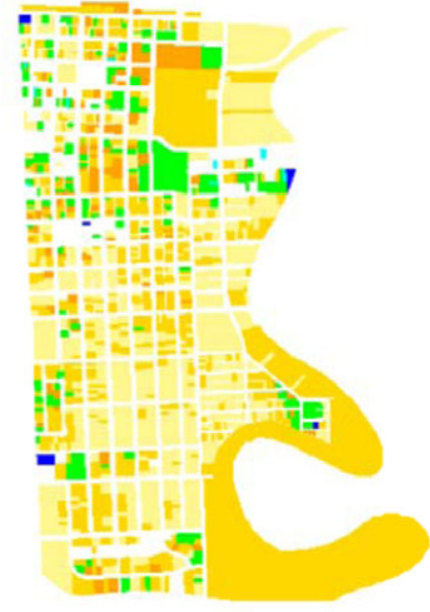

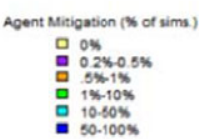

Year 51 Vacancy (LU-NB)

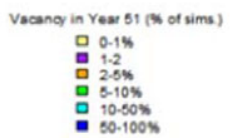

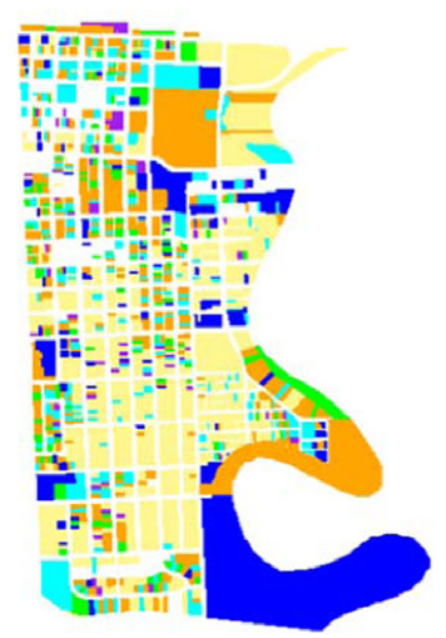

Fig. 11. Maps of Land Use-Neighbor results.

\section{CONCLUSIONS}

This study presents a new modeling approach for simulating the evolution of community flood risk. An $\mathrm{ABM}$ is used to simulate the influence of individual behavior on community flood risk. Barring influences like population and climate change, flood risk tends to decline in a community over time due to agent and community mitigation. Agent risk perception and coping perception are important influences. Agent mitigation and community mitigation are interconnected, with higher agent mitigation generally resulting in lower community mitigation, and vice versa.

In general, community mitigation results in reduced future damage. However, in some simulations,
Agent Mitigation (LU-NB)

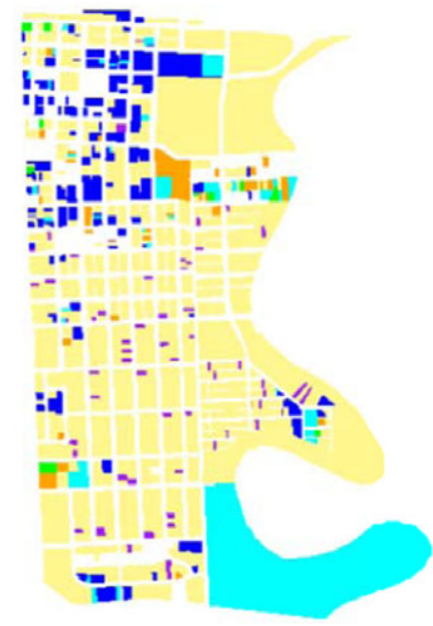

community mitigation is followed by a flood event that exceeds the mitigation height, resulting in substantial damage. Model runs with community mitigation tend to have higher total damage than those without, and this can generally be attributed to high damage events triggering the community action.

The use of an ABM for evolving flood risk allows for the relationship between flood events, individual action, and community action to be simulated. Individual action, including mitigation and movement in and out of high-risk areas, can have a significant influence on flood risk in a community. Furthermore, individuals are influenced by other individuals' experiences and actions, and this influence can also significantly affect how flood risk evolves. This was 
(a)
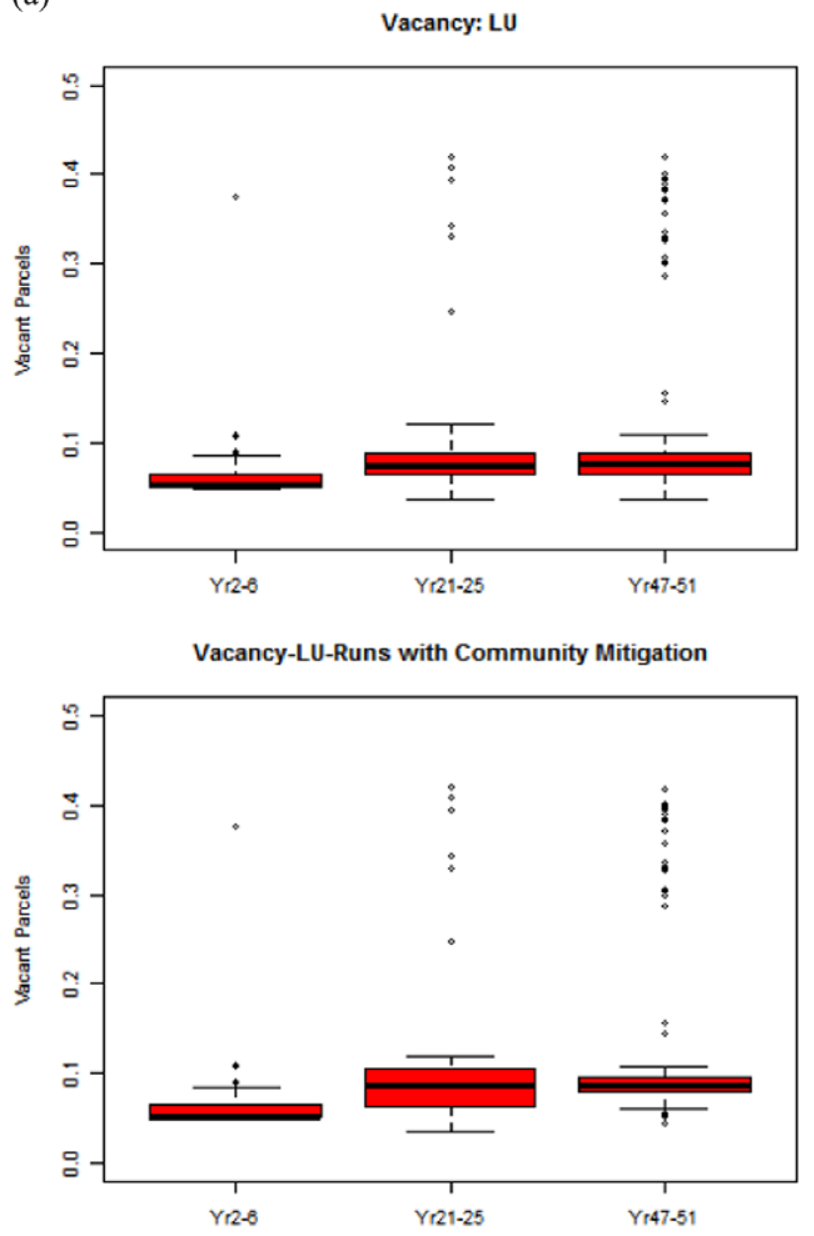

Vacancy-LU-Runs with no Community Mitigation

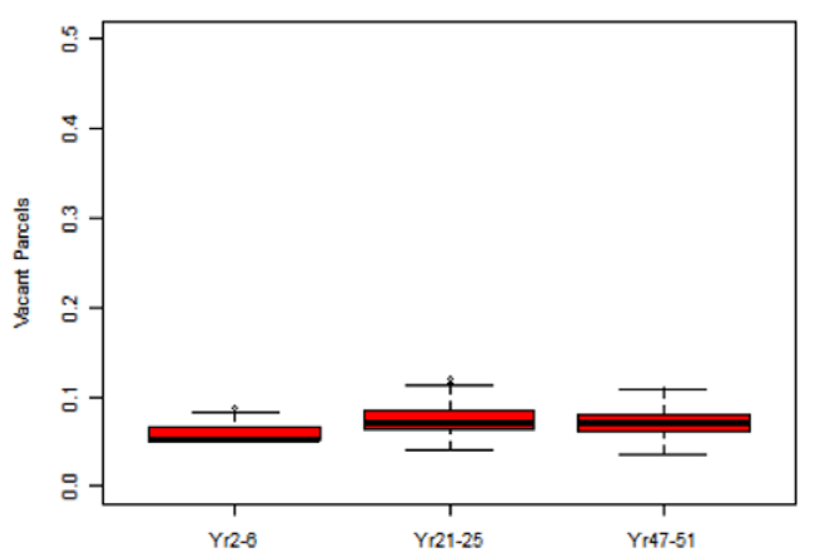

(b)
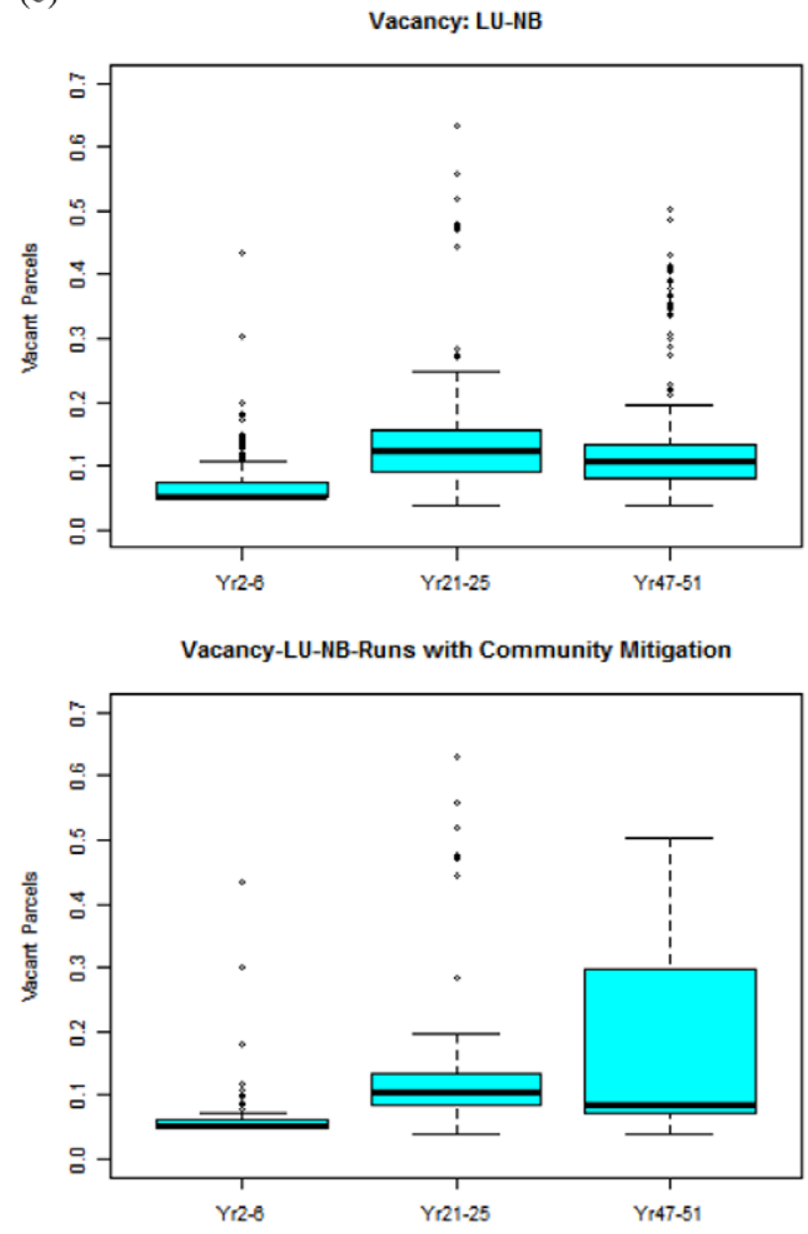

Vacancy-LU-NB-Runs with no Community Mitigation

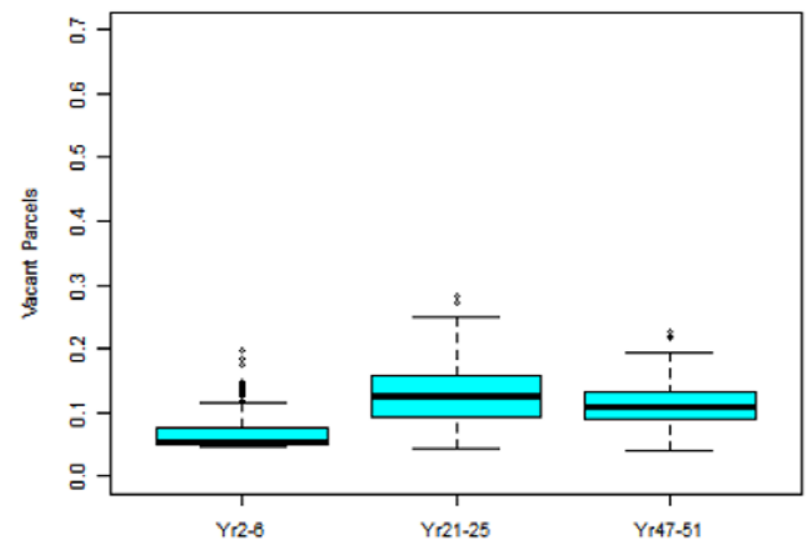

Fig. 12. (a) Vacancy, Land Use version. (b) Vacancy, LU-NB version. 
particularly evident in analysis of agent mitigation in the NB and LU-NB versions. Due to the importance of both movement and neighbor interactions on community flood risk, future models should continue to incorporate both of these features, and potentially refine the behavioral and decision rules associated with these model aspects.

The primary limitation to the use of an $\mathrm{ABM}$ for this application is that assumptions and simplifications need to be developed regarding behavioral rules for individual and community action. In this study, these took the form of thresholds for individual risk and coping perception, required number of complaints and damage for community action, and probabilities of individuals moving into at-risk areas. Because of this limitation, an extensive sensitivity analysis was run on these parameters to understand the effect that changes in the assumptions have on the model results. Details on the sensitivity analysis are available online as supplemental materials. In some cases, the model results were sensitive to changes in these parameters, and in other cases, they were not. In generating results for decision making in a particular community, it would be important to include behavioral rules specific to that community, in addition to physical hazard information for that community.

This study was a prototype for the use of ABM in simulating evolving flood risk in a community. Future work will include a more in-depth study of the evolution of flood risk in Fargo, ND and Moorhead, $\mathrm{MN}$, and potentially other locations. This will include surveys pertaining to individual and community flood risk perception and behavior, as well as detailed hydrologic and hydraulic modeling, and the use of additional downscaled future climate data. Future work will also simulate the impact of climate change on the evolution of community flood risk. The results of this study provide useful insights into how community flood risk evolves and also provide an understanding of how model parameters influence model outcomes, lending insight into priorities for future work.

\section{ACKNOWLEDGMENTS}

The work was partially funded by a U.S. National Science Foundation IGERT Water, Climate, and Health fellowship through the Johns Hopkins University and by an NSF Hazard SEES Grant (1631409).

\section{REFERENCES}

1. Wilby RL, Keenan R. Adapting to flood risk under climate change. Progress in Physical Geography, 2012; 36(3):348-378.

2. Kron W. Flood risk $=$ hazard $\bullet$ values $\bullet$ vulnerability. Water International, 2005; 30(1):58-68.

3. Criss RE, Everett L. Shock. Flood enhancement through flood control. Geology, 2001; 29(10):875-878.

4. Birkland TA et al. River ecology and flood hazard mitigation. Natural Hazards Review, 2003; 4(1):46-54.

5. Burn DH. Perceptions of flood risk: A case study of the Red River flood of 1997. Water Resources Research, 1999; 35(11):3451-3458.

6. Siegrist M, Gutscher H. Natural hazards and motivation for mitigation behavior: People cannot predict the affect evoked by a severe flood. Risk Analysis, 2008; 28(3):771-778.

7. Bubeck P, Botzen WJ, Aerts JC. A review of risk perceptions and other factors that influence flood mitigation behavior. Risk Analysis, 2012; 32(9):1481-1495.

8. Ludy J, Kondolf GM. Flood risk perception in lands "protected" by 100-year levees. Natural Hazards, 2012; 61(2):829842.

9. Wenger DE, James TF, Faupel CE. Disaster beliefs and emergency planning, University of Delaware Disaster Research Project, 1980.

10. Dooley D, Catalano R, Mishra, S, Serxner S. Earthquake preparedness: Predictors in a community survey. Journal of Applied Social Psychology, 1992; 22:451-470.

11. Lindell MK, Perry RW. Household adjustment to earthquake hazard: A review of research. Environment and Behavior, 2000; 32:590-630.

12. Tierney K, Lindell M, Perry, R. Facing the Unexpected: Disaster Preparedness and Response in the United States. Washington, DC: Joseph Henry Press, 2001.

13. Mileti DS, O'Brien P. Warnings during disaster: Normalizing communicated risk. Social Problems, 1992; 39(1):40-57.

14. Dow K, Cutter SL. Crying wolf: Repeat responses to hurricane evacuation orders. Coastal Management, 1998; 26:237-252.

15. Dillon RL, Tinsley CH. How near-misses influence decision making under risk: A missed opportunity for learning. Management Science, 2008; 54(8):1425-1440.

16. Dillon RL, Tinsley CH, Cronin M. Why near-miss events can decrease an individual's protective response to hurricanes. Risk Analysis, 2011; 31(3):440-449.

17. Tinsley CH, Dillon RL, Cronin MA. How near-miss events amplify or attenuate risky decision making. Management Science, 2012; 58(9):1596-1613.

18. Collmann J, Cooper T. Breaching the security of the Kaiser Permanente Internet patient portal: The organizational foundations of information security. Journal of the American Medical Informatics Association, 2007; 14(2):239-243.

19. Cooper T, Collmann J, Neidermeier H. Organizational repertoires and rites in health information security. Cambridge Quarterly of Healthcare Ethics, 2008; 17(04):441-452.

20. Koks EE, Jongman B, Husby TG, Botzen WJW. Combining hazard, exposure and social vulnerability to provide lessons for flood risk management. Environmental Science \& Policy, 2015; 47:42-52.

21. Birkholz S, Muro M, Jeffrey P, Smith HM. Rethinking the relationship between flood risk perception and flood management. Science of the Total Environment, 2015; 478: $12-20$.

22. Bubeck P, Botzen WJW, Kreibich H, Aerts JCJH. Detailed insights into the influence of flood-coping appraisals on mitigation behaviour. Global Environmental Change, 2013; 23(5):1327-1338.

23. Poussin JK, Botzen WW, Aerts JC. Factors of influence on flood damage mitigation behaviour by households. Environmental Science \& Policy, 2014; 40:69-77. 
24. Lindell MK, Hwang SN. Households' perceived personal risk and responses in a multihazard environment. Risk Analysis, 2008; 28(2):539-556.

25. Lindell MK, Perry RW. The protective action decision model: Theoretical modifications and additional evidence. Risk Analysis, 2012; 32(4):616-632.

26. Botzen WJW, Aerts JCJH, van den Bergh JCJM. Willingness of homeowners to mitigate climate risk through insurance. Ecological Economics, 2009; 68(8):2265-2277.

27. Brody SD, Kang JE, Bernhardt S. Identifying factors influencing flood mitigation at the local level in Texas and Florida: The role of organizational capacity. Natural Hazards, 2010; 52(1):167-184.

28. O'Connell PE, O'Donnell G. Towards modelling flood protection investment as a coupled human and natural system. Hydrol. Earth Syst. Sci. 2014; 18:155-171.

29. Terpstra T. Emotions, trust, and perceived risk: Affective and cognitive routes to flood preparedness behavior. Risk Analysis, 2011; 31(10):1658-1675.

30. Bonabeau E. Agent-based modeling: Methods and techniques for simulating human systems. Proceedings of the National Academy of Sciences, 2002; 99(suppl 3):7280-7287.

31. Evans TP, Kelley H. Multi-scale analysis of a household level agent-based model of landcover change. Journal of Environmental Management, 2004; 72(1):57-72.

32. Epstein JM. Generative Social Science: Studies in AgentBased Computational Modeling. Princeton, NJ: Princeton University Press, 2006.

33. Crooks AT, Heppenstall AJ. Introduction to agent-based modelling. Pp. 85-105 in Heppenstall A, Crooks A, See L, Batty M (eds). Agent-Based Models of Geographical Systems. Dordrecht, The Netherlands: Springer, 2012.

34. Berglund EZ. Using agent-based modeling for water resources planning and management. Journal of Water Resources Planning and Management, 2015; 04015025.

35. Epstein JM. Modeling civil violence: An agent-based computational approach. Proceedings of the National Academy of Sciences, 2002; 99(suppl 3):7243-7250.

36. Magliocca N, Safirova E, McConnell V, Walls M. An economic agent-based model of coupled housing and land markets (CHALMS). Computers, Environment and Urban Systems, 2011; 35(3):183-191.
37. Ng TL et al. An agent-based model of farmer decision-making and water quality impacts at the watershed scale under markets for carbon allowances and a second-generation biofuel crop. Water Resources Research, 2011; 47, W09519.

38. Zechman EM. Agent-based modeling to simulate contamination events and evaluate threat management strategies in water distribution systems. Risk Analysis, 2011; 31(5):758-772.

39. Dawson RJ, Peppe R, Wang M. An agent-based model for risk-based flood incident management. Natural Hazards, 2011; 59(1):167-189.

40. Kelton WD, Law AM. Simulation Modeling and Analysis. Boston: McGraw Hill, 2000.

41. Villarini G, Serinaldi F, Smith JA, Krajewski WF. On the stationarity of annual flood peaks in the continental United States during the 20th century. Water Resources Research, 2009; 45(8)

42. Lin S, Shaw D, Ho MC. Why are flood and landslide victims less willing to take mitigation measures than the public? Natural Hazards, 2008; 44(2):305-314.

\section{SUPPORTING INFORMATION}

Additional Supporting Information may be found in the online version of this article at the publisher's website:

Fig. S1: Sensitivity analysis for risk threshold.

Fig. S2: Sensitivity analysis for coping threshold.

Fig. S3: Sensitivity analysis for complaint threshold.

Fig. S4: Sensitivity analysis for damage threshold.

Fig. S5: Sensitivity analysis for risk threshold for moving.

Fig. S6: Sensitivity analysis for probability of moving in (without community mitigation).

Fig. S7: Sensitivity analysis for probability of moving in (with community mitigation). 